\title{
El uso del concepto de "ciudadanía" en el trabajo jurídico de Pedro José Agrelo entre 1813 y 1822 en el Río de la Plata
}

\author{
The use of the concept of "citizenship" in the legal work of Pedro José Agrelo between 1813 and 1822 in the Río de \\ la Plata \\ Ariel Alberto Eiris \\ DOI: https://doi.org/10.24215/23468971e119
}

CONICET; Universidad Católica Argentina; Universidad

del Salvador, Argentina

eirisariel@gmail.com

Recepción: 14 Junio 2020

Aprobación: 02 Julio 2020

\section{RESUMEN:}

El presente análisis indagará en el trabajo del letrado rioplatense Pedro José Agrelo, quien como jurista participó de la redacción de dos proyectos constitucionales. En ambos se esbozaron diferencias en el concepto de "ciudadanía”. Ello implica el estudio del lenguaje en diálogo con la aplicación práctica que el jurista buscaba realizar. Frente a la problemática por el sentido que esta concepción tenía para un letrado de activa participación como Agrelo y la forma en que la misma fue aplicada en sus intervenciones políticas y de gestión, entendemos que esta categoría le facilitaba a Agrelo edificar una estructura jurídica de carácter republicano que le permitía romper con el sistema absolutista. Sin embargo, esta definición teórica se traslucía en una práctica ambigua centrada en favoritismos y preferencias al momento de integrar a la categoría de ciudadano a quienes no eran nativos del territorio. Allí se puede evidenciar entonces los intereses políticos y personales que actuaban y los problemas por aplicar los nuevos lenguajes políticos en el marco de la elaboración de una definición jurídica.

Palabras Clave: Pedro José Agrelo, Ciudadanía, Asamblea del Año XIII, Estatuto Provincial de Entre Ríos.

\section{Abstract:}

The present work explores the work of Pedro José Agrelo as lawyer and jurist, who participated in the drafting of two constitutional projects, where differences in the concept of "citizenship" were outlined. This implies the study of language in dialogue with the practical application that the jurist sought to carry out. Faced with the problem by the sense that this conception had for a lawyer of active participation as Agrelo and the way in which it was applied in its political and management interventions, we understand that this category facilitated Agrelo to build a legal structure of character republican that allowed him to break with the absolutist system. However, this theoretical definition was reflected in an ambiguous practice focused on favoritism and preferences when integrating citizens who were not native to the territory. There you can see then the political and personal interests that acted and the problems of applying the new political languages in the framework of the elaboration of a legal definition.

KEYWORDS: Pedro José Agrelo, Citizenship, Assembly of the Year XIII, Provincial Statute of Entre Ríos.

\section{INTRODUCCIÓN1}

La trayectoria política e intelectual de Pedro José Agrelo (1776-1846) se desarrolló en el Río de la Plata, a través de una relevante actividad jurídico-política. Tras un rápido ingreso y ascenso en la administración borbónica en el Alto Perú, integró los sectores revolucionarios de Buenos Aires a partir de principios de 1811. Desde allí se desenvolvió como periodista, integrante de la Cámara de Apelaciones, fiscal del juicio contra Martín de Álzaga (1812), miembro de la Logia Lautaro, diputado y presidente de la Asamblea del Año XIII, donde promovió la acuñación de moneda soberana y colaboró en la presentación de un proyecto de constitución. Allegado a Carlos de Alvear, conspiró contra el gobierno de Juan Martín de Pueyrredón lo que le valió el exilio en Estados Unidos en 1817 donde se vinculó con pensadores federales norteamericanos. Participó de los gobiernos débiles de Buenos Aires en 1820 donde promovió el "motín del Cabildo" del $1^{\circ}$ de octubre. Exiliado en Entre Ríos colaboró en la redacción de su Estatuto Provincial en 1822. 
Todo ello evidencia su importancia dada su activa y significativa presencia en los acontecimientos claves de la época de la Independencia, lo que se sustenta en una amplia bibliografía que si bien lo mencionó, no se detuvo en su estudio en articular. ${ }^{2}$ Así, el presente trabajo se inscribe dentro del marco general de la investigación sobre su trayectoria político-jurídica, que permite desentrañar las formas en que el letrado en cuestión se vinculó a los sucesivos gobiernos y actuó en función de ellos dando aportes administrativos y teóricos según las necesidades coyunturales. ${ }^{3}$ Este artículo se centrará exclusivamente en los trabajos realizados por Agrelo donde se desarrolló el concepto de "ciudadanía" en diálogo con la aplicación práctica que el letrado realizaría en dos momentos centrales de su labor jurídica, durante la Asamblea de 1813 y el Estatuto Provincial de Entre Ríos 1822.

Dicha categoría fue objeto de numerosos trabajos en la historiografía argentina referidos a su utilización a principios del siglo XIX. Entre ellos han sobresalido los enfoques institucionales y jurídicos que centraron su análisis en el surgimiento del concepto de "ciudadano" en el espacio rioplatense, como nueva definición del sujeto soberano. Algunos aportes han señalada la importancia de una transformación lineal de los criterios de "súbdito" y "vecino" al de "ciudadano" en el mundo hispánico en general (Pérez Guilhou, 2001; Casanello, 2003; Pérez Ledesma, 2008; Martiré y Tau Anzoátegui, 2012, p. 422-423). En este sentido, se evidenció cómo el término "ciudadano" hacía referencia al integrante de la comunidad política, definido por un carácter de igual frente a sus pares, en oposición al "súbdito" que refería a una organización política jerárquica definida por la subordinación a un monarca. En ese aspecto, "ciudadano" aludía a un sistema regido por el principio de "soberanía popular", mientras que el de "súbdito" reconocía una soberanía real.

Sin embargo, esta problemática fue complejizada con el aporte de otros estudios que han profundizado en las connotaciones previas del lenguaje "ciudadanía" y su coexistencia con categorías como "vecino" en la cultura política española (Herzog, 2006; Aljovin de Losada, 2014, p. 179-210). Dado los localismos fuertes centrados en la organización política de las ciudades hispánicas que se autodenominaban "repúblicas”, existía un trato de "ciudadano" hacia aquellos que podían tener participación política en el gobierno de la ciudad. Era entonces un principio de carácter urbano, asociado al de "natural", el cual refería al nacido o integrado a la comunidad urbana local, en oposición al forastero. Algunos naturales adquirían a su vez el título de "vecino" al reunir los requisitos para ser un actor político que podía ejercer cargos públicos y participar de los debates del cabildo. Es por ello, que, al momento de constituir un nuevo sistema jurídico a principios del siglo XIX, se re-significó el concepto de "ciudadanía”, el cual se generalizó fuera del espacio urbano local y acabó por reemplazar al "súbdito", aunque también terminó por desplazar al "vecino" y al "natural”. Así, quedó constituido como único lenguaje referente de los miembros de la comunidad que eran parte del sujeto soberano.

Dentro de estas conceptualizaciones historiográficas, fueron relevantes aquellos que analizaron la vinculación del "ciudadano" con las nuevas prácticas electorales, lo que permitió comprender las formas políticas en que operaba el concepto e influía en los debates jurídicos de la elite dirigente (Sábato, 1999; Casanello, 2001, p. 143-169; Sábato y Ternavasio, 2011). Asimismo, se produjeron renovados aportes que acentuaron la utilización y el sentido que adquiría el otorgamiento de "cartas de ciudadana" en la tensión entre los poderes políticos locales y el gobierno central revolucionario (Salvatto y Banzato, 2017, p. 169-195). Dichas cartas eran concesiones del poder soberano, que reemplazaron las "cartas de naturalidad", al convertir al extranjero en integrante de la nueva comunidad política que se buscaba constituir.

Otras investigaciones se centraron en un mayor carácter social, a través del cual buscaron entender las formas en que esta concepción era tomada por la sociedad, mediante mecanismos de utilización y reproducción de prácticas que acabaron por integrarse al entramado cultural rioplatense (González Bernarndo, 1991, p. 7-27; Molina, 2002). En este mismo enfoque, también sobresalieron aquellos estudios que vieron su utilización por parte de los sectores bajos y la forma en que se produjo su expansión conceptual, como nueva categoría de integración (Di Meglio, 2007, p. 137-158). De esa forma, se fue constituyendo una cultura política, previa a su instauración jurídica. 
La confluencia de todos estos trabajos permite un acercamiento general a la conceptualización y la práctica derivada de la categoría de ciudadano. Muchas de ellas refieren la presencia de Agrelo en los debates jurídicos producidos, aunque ninguna se detuvo especialmente en su aporte. De allí, emerge la problemática por el sentido que esta concepción tenía para un letrado de activa participación como Agrelo y la forma en que la misma fue aplicada en sus intervenciones políticas y de gestión. Se entiende que esta categoría adquirió connotaciones diferentes, en la medida que eso le permitía a Agrelo edificar una estructura jurídica que diera orden a la participación política y sentara bases para una nueva organización social de carácter republicano que le permitía romper con el sistema absolutista. Sin embargo, esta definición teórica se traslucía en una práctica ambigua centrada en favoritismos y preferencias al momento de integrar a la categoría de ciudadano a quienes no eran nativos del territorio. Allí se puede evidenciar entonces los intereses políticos y personales que actuaban y los problemas por aplicar la definición jurídica esbozada.

Para realizar este análisis nos centraremos en los documentos de gobierno de la Asamblea de 1813 y en el proyecto constitucional de la Comisión Oficial integrada por Agrelo en ese año, en diálogo con sus memorias y sus publicaciones periodísticas, además del Estatuto Provisional de Entre Ríos de 1822. Ambos años representan dos "momentos constitucionales" ${ }^{4}$ donde el letrado participó del plasmado de una idea de "ciudadanía" que respondía a diferentes coyunturas, pero que permite comprender la forma en que operaba el principio y las prácticas asociadas al mismo. Para ello, será central el uso de herramientas metodológicas provenientes de la historia de los conceptos, que permitirán comprender los cambios semánticos y contextuales producidos en la utilización del lenguaje jurídico, ${ }^{5}$ a la vez que se tomarán aspectos de la renovada historia política y del derecho a fin de dilucidar la relación entre la definición teórica y la práctica realizada por el jurista en cuestión. ${ }^{6}$

Para ello se utilizará la categoría analítica de "letrado", entendido como un "hombre de saber", una persona formada y preparada en conocimientos eruditos, pero con centralidad en el aspecto jurídico, para el servicio del orden político. ${ }^{7}$ Como tal, Agrelo se desempañó como diputado, legislador y jurista a lo largo de los ámbitos regionales e institucionales en donde actuó, para formular y utilizar desde allí el concepto de "ciudadanía" que circulaba por sus espacios socio-políticos. Es importante considerar a Agrelo como parte de tramas relacionales y grupos políticos desde los que debió actuar. No fue un letrado aislado, sino un actor que respondía con grados de originalidad, pero desde espacios a los que pertenecía y que lo condicionaban.

El análisis centrado en su figura permitirá ver así la transformación del uso del concepto, en función de las diferentes coyunturas y grupos a los que pertenecía. Por todo ello, el trabajo se estructurará en un primer momento en el estudio del lenguaje de "ciudadanía" que se utilizaba y discutía en la Sociedad Patriótica que Agrelo integraba, para ver luego su planteo constitucional y su aplicación práctica en 1813 y finalmente su nueva definición en el Estatuto Provincial de Entre Ríos en 1822. Para eso, se tomará como fuentes las publicaciones de la Sociedad Patriótica, los documentos oficiales de gobierno referidos al concepto señalado y principalmente los textos constitucionales de 1813 y 1822 sumados a las memorias conservadas de Agrelo.

\section{LAS PRIMERAS REFERENCIAS A LA CIUDADANÍA, EN EL ÁMBITO DE LA CULTURA POLÍTICA DE} Agrelo

Como letrado formado bajo la "ilustración católica" ${ }^{8}$ de la monarquía borbónica, Agrelo fue un agente receptor y formulador de lenguajes políticos en circulación. Su primera vinculación con el término de "ciudadanía" se evidencia en 1811, cuando empezó a desempeñarse como colaborador del proceso revolucionario en vinculación directa con los sectores morenistas y la Sociedad Patriótica que integraba. Dicha asociación era un espacio de socialización en el cual emergió el trato de "ciudadano" entre sus miembros, como forma de constituir una cultura política que rompiera con la jerarquía monárquica, lo que significaba una extensión progresiva de la participación política (González Bernaldo, 1991). Desde ese 
espacio de sociabilidad, Agrelo permanecía informado de los cambios políticos mediante su actuación como redactor de la Gazeta de Buenos Ayres ${ }^{9}$ y luego como fiscal de la Cámara de Apelaciones.

En el orden jurídico, por ese entonces, en 1811 el Primer Triunvirato inició la entrega de "cartas de ciudadanía" a extranjeros que tenían una trayectoria política próxima al proceso revolucionario o que habían tenido participación en sus gobiernos o ejércitos. Dichas cartas reempezaban las "cartas de naturalidad" dadas en la época virreinal a los extranjeros establecidos en la ciudad. Era una forma de integrarlos a la comunidad política local, al adjudicarle facultades políticas, pero bajo la nueva cultura política que se buscaba constituir. Así, su integración a la comunidad local implicaba directamente su acceso al espacio político y público. Como "carta" seguía siendo una concesión del poder soberano, que por entonces pasaba a ser representado por el gobierno revolucionario en nombre del rey ausente.

La estrategia de entrega de cartas de ciudadanía, servía al gobierno para fortalecer la distinción entre revolucionarios y realistas, a la vez que integraba al cuerpo político a los peninsulares o extranjeros en general, que respaldaran el proceso iniciado en 1810. La carta de ciudadanía le daba marco jurídico a esa distinción de personas dentro de la nueva cultura política, mientras actuaba como elemento coercitivo hacia los individuos reacios a aceptar el vigente orden.

Uno de los primeros en recibir dicha concesión fue Robert Billinghurst, cuñado de Agrelo ya que estaba casado desde 1810 con su hermana Francisca Agrelo. ${ }^{10}$ El británico había logrado mantener una posición social de prestigio en Buenos Aires, a la vez que se había integrado a las redes socio-políticas de la familia Agrelo, que tenían en Pedro José al principal agente vinculado con el gobierno. Eso implicaba que el gobierno revolucionario tenía confianza en Billinghurst, posiblemente dada su integración a las redes socio-políticas en las que actuaba Agrelo.

Esta carta era a nombre del rey, dado el reconocimiento que su figura había tenido por los sucesivos gobiernos revolucionarios. Seguí el mismo esquema de redacción que las otorgadas por entonces en las Cortes de Cádiz, las cuales se encontraban en un proceso jurídico similar de conformación de "ciudadanos" (Salvatto y Carzolio, 2015, p. 670-706). Allí se evidencia la tensión entre la coexistencia de principios que tendían a superponerse. El dar carta de vecindad, implicaba la supresión de la naturalidad, y a su vez la conformación de un actor político, lo cual era hasta entonces el "vecino". Éste actor social era un residente de la ciudad que debía ser propietario, con un estatus y jerarquía reconocida, siendo cabeza de familia e integrante de una corporación social, que tenía participación política con voz y voto en el Cabildo (Tanzi, 2000, p. 325). La vecindad otorgaba facultades políticas locales, con un fuerte componente del ius sanguinis, donde las relaciones familiares resultaban claves para que el advenedizo pudiera integrarse al cuerpo social y obtener presencia pública. Mientras que la "ciudadanía” partía de la concepción de igualdad jurídica e individualidad propia de la Ilustración. Así, la "ciudadanía” designaba al portador de los derechos y obligaciones, en paridad con el resto de los integrantes del cuerpo social, pero con un alcance general, más allá del espacio local de la ciudad (Molina, 2002, p. 144).

Esta cuestión general en el mundo hispánico, tuvo una particular tensión en el Río de la Plata, dada la progresiva radicalidad del proceso revolucionario. La Sociedad Patriótica de la que participaba Agrelo, pasó a expresar su rechazo a la continuidad de la referencia al rey y la incongruencia de que la ciudadanía sea en nombre suyo y no directamente de la comunidad política local. Esa situación, en otras, marcaba el desgaste político entre la posición exaltada de la Sociedad Patriótica y la moderación del Primer Triunvirato, lo que desembocó en la Revolución del 8 de octubre de 1812 de la que Agrelo participó, mediante la cual fueron depuestas las autoridades políticas. La Sociedad Patriótica en convivencia con la Logia Lautaro -a la que Agrelo se incorporaría ese mismo año-, impusieron un nuevo triunvirato que convocó al postergado Congreso General que se reuniría finalmente en 1813.

Antes de las elecciones de los integrantes de la futura Asamblea, el nuevo Triunvirato designó el 4 de noviembre una Comisión Oficial con el objetivo de que preparara y discutiera las materias que serían presentadas para su legislación. Esa solicitud era acompañada por el pedido que al mismo tiempo se redactara 
un proyecto de Constitución. Según la Gazeta Ministerial, la normativa se debía a la necesidad de "construir el edificio político de estas provincias" (Gazeta Ministerial, 13 de noviembre de 1812), cuyos cimientos sentaría la Comisión constituida.

Entre los integrantes de la Comisión se encontraban varias de las figuras que habían colaborado con la Revolución del 8 de octubre y que integraban la Logia Lautaro como el propio Agrelo, José Valentín Gómez e Hipólito Vieytes, junto a otras personalidades allegadas como Pedro Somellera, Manuel José García, Nicolás Herrera y Luis Chorroarín, quien sería sustituido posteriormente por Gervasio Antonio Posadas, otro logista ${ }^{11}$. Todos ellos, eran hombres vinculados coyunturalmente en la misma tendencia política preponderante, aunque tendrían trayectorias disímiles. Por entonces eran representantes de los principios sostenidos por el nuevo Triunvirato, y considerados como letrados experimentados en diversas áreas vinculadas al funcionamiento institucional ${ }^{12}$. Todos los tribunales, corporaciones, oficinas y ciudadanos particulares estaban obligados a suministrar los conocimientos y relaciones que la Comisión les solicitara (Canter, 1966, p. 67). Desde ese seno organizativo, Agrelo empezó su colaboración como redactor de un proyecto constitucional desde antes de su elección e incorporación a la Asamblea.

Ante su trabajo como jurista en los preparativos previos y su elección como diputado de la Asamblea, Agrelo destacaba en sus memorias su concepción "firme y decidida" por una pronta declaración de la independencia, la cual anteponía a cualquier otra medida. Según la lógica expresada, todas las decisiones del cuerpo legislativo deberían estar en coherencia con dicho objetivo central, de manera que el derecho respaldara la libertad adquirida en los hechos. Ello se expresaba en los escritos de Agrelo, para quien la solución jurídica sólo podría venir de una Constitución apropiada. La misma representaría el marco legal que garantizaría un nuevo orden a los territorios independizados. Sin embargo, en el lenguaje de la época el término tenía una doble salvedad: en lo que respecta a la concepción racionalista que la entendía como una ley fundamental organizada y sistematizada en un único texto, a diferencia de su concepción antigua y escolástica referida como el conjunto de leyes que constituían y estructuraban la organización política (Halperin Donghi, 1985, p. 96; Portillo Valdés, 2009, p. 307-335). Su referencia era ambivalente con respecto a ambos significados, aunque prevalecía la perspectiva moderna. ${ }^{13}$ Esto se evidencia en que los cuatro proyectos presentados fueron de una Constitución moderna, aunque en los hechos la Asamblea optaría por legislar conjuntos de leyes soberanas.

Desde ambos sentidos, el referir a la creación de una "constitución" significaba la codificación de los parámetros de conductas, individuales e institucionales, rompiendo con el sentido consuetudinario y causalista del derecho hispánico tradicional. Ello implicaba la consolidación de un sujeto soberano, el "ciudadano", sobre el cual se pudiera desarrollar la esquematización de derechos y obligaciones a partir de una lógica cívica igualitaria que coincidía con los lenguajes sostenidos por los grupos más radicales de la Revolución. Así, desde principios abstractos y racionales se pretendía dar un respaldo jurídico al orden político que en los hechos se había constituido, para lograr su legitimación interna y el reconocimiento externo, además de lograr la estabilidad institucional y social. Esa tarea era asumida por la "voluntad racional de los juristas", como Agrelo, quienes asumían una facultad despojada del Estado dieciochesco (Tau Anzoátegui, 2008, p. 34-35).

Eso implicaba una nueva imagen del cuerpo político y social, intrínsecamente vinculado al contexto de crisis atlántica que condicionaba aquella necesidad de codificación. A su vez, eso se daba en un marco de originalidad especial, donde se evidenciaban los procesos de circulación y recepción de conceptos aplicados a la realidad local rioplatense, lo que implicaba un "arte político" de articulación de tradiciones hispanoamericanas con nuevos lenguajes y prácticas que dieran respuestas concretas a los problemas específicos de la sociedad rioplatense (Aninno y Ternavasio, 2012). Las definiciones del ejercicio de la soberanía que se debían dar, implicaban la definición y conceptualización de la "ciudadanía" en términos jurídicos y empíricamente aplicables. 
La forma en que esta categoría operó en el diseño jurídico, requiere un estudio especial, por constituir un "momento constitucional" que permite analizar la articulación plasmada de conceptos jurídicos realizados en aquel momento, como respuesta a las problemáticas tratadas. A su vez, eso permitirá ver las definiciones aceptadas por Agrelo, además de dilucidar sus aportes específicos en el proyecto de Constitución elaborado por la Comisión de la que formó parte y la definición que la misma acabó por darle al concepto de ciudadanía.

\section{El proyecto de Constitución de la Comisión Oficial de 1813}

Luego de dos meses y medio de trabajo e iniciadas las sesiones de la Asamblea, la Comisión Oficial que Agrelo integraba presentó al Triunvirato su proyecto de Constitución, el cual debía ser discutido inmediatamente después de la aprobación de la independencia. La vocación independentista de sus redactores quedaba señalada ya desde el artículo $1^{\circ}$ del Capítulo I donde se establecía que: "las provincias del Río de la Plata, forman una República libre e independiente". ${ }^{14} \mathrm{El}$ mismo artículo denotaba la tendencia republicana que poseían los integrantes de la Comisión y que exponían como idea firme y aceptada, a pesar de la falta de apoyo extranjero que con posterioridad pondría en cuestionamiento dicha postura. El lenguaje de "república" que se esbozaba refería a un sistema caracterizado por la división de poderes y la consolidación de leyes aplicables para todos los sujetos soberanos, que recibirían la categoría de ciudadanos.

Los fundamentos teóricos del proyecto se sustentaban en la lógica del derecho natural que legitimaba a la Revolución de Mayo desde sus inicios (Chiaramonte, 2000, p. 22). Esa concepción era amplia y ambigua, ya que integraba las corrientes iusnaturalistas de Hugo Grocio y Samuel Pufendorff, junto a la escolástica española y a las concepciones contractuales de la ilustración franco-inglesa, bajo el marco de organización jurisdiccional que había mantenido la monarquía española. A su vez, la Constitución de 1812 sancionada por la Cortes de Cádiz y que respondía a las mismas bases ideológicas, actuaba como un arquetipo a seguir, aunque no podía ser referido como tal debido a la ruptura política existente con la península (Aninno y Ternavasio, 2012).

En apelación a ese eclecticismo, el artículo 2 justificaba la Independencia, mediante la mención de que "la soberanía del Estado reside esencialmente en el pueblo", lo cual era aclarado en el siguiente artículo al asegurar que "el pueblo es la reunión de todos los hombres libres de la república" (Universidad de la República, 1932, p. 150). Esto evidencia las connotaciones modernas del proyecto al hablar de una soberanía depositaria en un pueblo fruto de la unión de individuos iguales y no en la unión de "pueblos", terminología que remitiría a la concepción del poder jurisdiccional. Pese a eso, la continuidad de concepciones corporativas centradas en colectivos sociales como "familia" y "pueblos", obligaba a los juristas a realizar el esfuerzo por integrar la representación social tradicional con el ideal liberal francés de "ciudadano" que pasaba a ser la nueva unidad básica de la sociedad.

Sobre esas bases conceptuales asumidas por todo el cuerpo de redactores, se desprenden la totalidad de los articulados desarrollados. En ese conjunto de elementos, la documentación personal conservada por Agrelo permite aproximarse a los principales aspectos en los que se centró su contribución en la Comisión Oficial. Estos son esencialmente: la política anti-española presente en el otorgamiento de título de ciudadanía; la conformación de un poder legislativo fuerte y representativo de corporaciones sociales; y la organización del poder judicial, en especial mediante la aceptación del juicio por jurado. A pesar de representar tres ejes diferentes, ellos se encontraban articulados bajo una misma lógica conceptual, de la cual sólo se trabajará la política de entrega de cartas de ciudadanía. ${ }^{15}$

Agrelo aseguraba en sus memorias haber promovido un espíritu combativo hacia los realistas en la Asamblea (Agrelo, 1960, p. 1313). Eso queda también evidenciado en sus textos personales, donde se mencionaba la "falta de confianza" que la guerra generaba hacia el español peninsular. Desde 1811 mantuvo un estilo retórico combativo, reflejado igualmente en sus discursos en la Gazeta y en el juicio contra Álzaga, 
que fortalecía el quiebre conceptual entre criollos y peninsulares que el proceso revolucionario estaba acentuando.

Estas ideas expuestas con anterioridad, estaban igualmente señaladas en la redacción de la Constitución. Allí, tras detallar los mecanismos y características para la entrega de títulos de ciudadanía y las causas por la que ésta podía ser retirada, se dedicaba el artículo 5 del Capítulo VI al mencionar la "actitud hostil con que la generalidad de los españoles europeos ha observado constantemente contra la libertad de las Provincias Unidas" (Universidad de la República, 1932, p. 152). Ello podría aludir de forma indirecta a la crisis generada el año anterior con la conspiración de Álzaga que había despertado políticas anti-peninsulares. Tras una prolongada crítica a los realistas escrita en un estilo propio de un artículo periodístico, condicionaba la entrega del título de ciudadano al reconocimiento español de la independencia. El artículo carecía de normativa, por lo que representaba una argumentación política que sustentaba la articulación siguiente.

Se sostenía en el Capítulo V la existencia de los "Derechos del Ciudadano" los cuales mantenían una importante influencia francesa, aunque sus artículos resumían los conceptos generales en dos puntos esenciales, por lo que evitaba reproducir la totalidad de los derechos colocados en las Constituciones francesas. Sobre estos principios, el proyecto presentaba capítulos especiales para el ejercicio de determinados derechos civiles y políticos. Sin embargo, todos ellos eran luego restringidos a los nacidos en el país y los naturalizados, pero exceptuando a los españoles europeos salvo aquéllos que "el Congreso reconociera por sus servicios a la Revolución".

El concepto de ciudadano quedaba fuertemente arraigado al aseverarse en el capítulo 4, artículo 1 que: "son ciudadanos los hombres libres que, nacidos y residentes en el territorio de la República, se hallen inscriptos en el registro cívico. Ningún hombre nace esclavo en el territorio de la República, desde la aceptación de la Constitución”. Esto difería con las propuestas de la Sociedad Patriótica que condicionaba el ejercicio del derecho de ciudadano a la capacidad de leer y escribir, no así sus derechos civiles. La ciudadanía concebida en este proyecto era de carácter "moderno", al establecerla de carácter individual e igualitario, sin la referencia a las “cabezas de familia" propia de la lógica política tradicional en España. ${ }^{16}$ Pese a ello, permanecía la referencia a su carácter de "residente", en alusión a su permanencia física en el territorio, lo que solía de referirse con su título de propiedad, pese a que este aspecto no es detallado en el proyecto.

A su vez, el artículo señalaba la "libertad de vientre" con anterioridad a que la Asamblea la aprobase. Al igual que la ley que la Asamblea aprobaría más adelante, se declaraba libres a todos los hombres nacidos en el territorio, sin negar la condición de esclavo a quienes ya lo eran. Esto implicaba una abolición gradual y prolongada en el tiempo (Di Meglio, 2007).

Además del proyecto constitucional de la Comisión Oficial, la Sociedad Patriótica presentó otro, donde se hacían diferencias en la concepción de ciudadanía. Este proyecto que contó con la colaboración de Monteagudo limitaba el sujeto soberano a los alfabetizados, mientras que la Comisión Oficial no se ocupaba de este problema. Se constituyó un tercer proyecto que intentaba articular ambos modelos constitucionales, además del presentado por los diputados antigüistas que fueron rechazados.

Sin embargo, pese a estas definiciones jurídicas y al esfuerzo allí volcado, según las memorias de Agrelo, la Asamblea consideró que no era oportuno debatir los proyectos constitucionales (Agrelo, 1960, p. 1314). Pese a ello, se podrían tomar medidas que si bien no constituyeran una constitución moderna, representaran un cuerpo normativo fundamental para la organización del nuevo sistema institucional. Por ello, los primeros meses de la Asamblea se caracterizaron por un fuerte impulso de leyes consideradas soberanas. Gracias a las influencias de la Logia Lautaro, Agrelo logró integrar la Asamblea como diputado por Salta, e incluso alcanzó el cargo de Presidente de la misma durante abril de 1813. Desde allí, el letrado podría proseguir con la sanción de normativas tendientes a continuar la concepción de ciudadanía esbozada en el proyecto, a la vez que tendría la oportunidad de actuar y tomar medidas directas en su aplicación. 


\section{LA Asamblea del AÑo XIII y la APliCACión de la CiUdAdanía Rioplatense}

Uno de los aspectos en que se destacó la intervención de Agrelo en la Asamblea, fue en el asunto de la relación con los españoles peninsulares. Tanto los escritos periodísticos, como sus prácticas jurídicas y el proyecto de Constitución del que había participado indicaban su pertenencia a la línea política más dura en lo referido a la reacción contra este sector social en general. Agrelo fue, junto con Monteagudo, de los principales exponentes de la posición que reclamaba el desplazamiento de los españoles peninsulares de los espacios de poder. ${ }^{17}$

A pesar de la participación de varios de ellos en el proceso revolucionario, la tendiente radicalidad y la posición independentista causaba una ascendente tensión con aquellos. La guerra fue el principal factor promotor de esta situación, que llegó a su máxima expresión con los sucesos de la conspiración de Álzaga y el consecuente desarme de quienes que no eran criollos. Letrados como Agrelo veían en la presencia peninsular un problema a solucionar al momento de constituir al nuevo actor soberano.

Esta cuestión adquiría una relevancia especial al definir la entrega de los títulos de ciudadanía, lo que representaba la creación de un sujeto político capaz de elegir y ser elegido, siendo un elemento clave en la construcción del nuevo poder político que reemplazaba el régimen colonial (Cansanello, 2003, p. 14-15). La determinación de quién era ciudadano implicaba su posibilidad de ejercer cargos públicos y participar del gobierno. Ello significaba una división que no estaba clara al momento del inicio de la Revolución, pero que figuras como Agrelo promovieron acentuar. La concepción moderna de ciudadanía que se desarrollaba como práctica, especialmente desde la organización de la Sociedad Patriótica, adquiría allí su definición jurídica como elemento determinante tanto de derechos políticos y cívicos, como de obligaciones contraídas. El mismo reemplazaba así al de súbdito y rompía la jerarquía propia del sistema monárquico hispánico. En consecuencia, la entrega o negación de dicho título, se convertía en un elemento de presión política hacia un sector social que podía resultar conflictivo.

Además, el otorgar la carta de ciudadanía era un elemento central en la definición teórica del lugar donde radicaría la "soberanía". Los primeros títulos fueron dados por el Primer Triunvirato y decían otorgarse en nombre del rey, reconociendo en su figura el depositario de la soberanía, aunque con un fuerte espíritu localista que tomaba distancia de otros ejes en la colapsada monarquía policéntrica. Meses después la fórmula legal fue modificada por el mismo gobierno, estableciendo el título de "ciudadano americano del Estado de las Provincias Unidad del Río de la Plata” (Gazeta Ministerial, 24 de julio de 1812, p. 4).

El mismo no fue cambiado por la Asamblea, aunque se profundizaría el debate en torno a la cuestión. Se mantuvo la otorgación del título sin requisito de edad, años de residencia, ni propiedad, solamente quedaba supeditado a la consideración de la entidad gubernamental. ${ }^{18}$ La Asamblea había dispuesto como único mecanismo para la solicitud del título, que sin excepción sería el cuerpo legislativo -cómo único depositario de soberanía- el que otorgara la ciudadanía. Para su obtención se exigía una decisiva adhesión a la causa americana, habiendo colaborado también con servicios públicos en su mantenimiento y defensa, renunciando a la vez a toda pensión europea (Canter, 1966, p. 144-145), lo que asimilaba esta condición al título de "natural" dado en el régimen monárquico indiano. ${ }^{19}$

La problemática tuvo gran relevancia dentro de los debates del cuerpo legislativo. El mismo dispuso en una de sus primeras sesiones que sean "removidos de los empleaos eclesiásticos, civiles y militares europeos residentes en esta ciudad, que no -hubieran- obtenido en este término el título de ciudadanía”. ${ }^{20}$ Ello coincidía con lo estipulado por el proyecto constitucional de la Comisión Oficial en su artículo 4 del Capítulo VI. La medida representaba la determinación por la fuerza de que los peninsulares ingresaran al sistema de gobierno mediante la aceptación de la nueva soberanía y de los consecuentes sujetos soberanos, o quedarían definitivamente excluidos del funcionamiento político.

Los debates por esta cuestión continuaron. En alguna de sus intervenciones en la Asamblea, Agrelo acentuó y defendió oralmente las restricciones expresadas en el proyecto constitucional. Cuando fue presidente de la 
misma en el mes de abril de 1813, promovió una medida para acelerar los plazos de solicitud del título de ciudadanía. Consiguió que el cuerpo legislador declarara que todos los españoles europeos tendrían un plazo de entre ocho días y diez meses según su ubicación para solicitar el título, o quedarían excluidos del mismo (El Redactor de la Asamblea, 10 de abril de 1813). Hubo muchas presentaciones, aunque un alto porcentaje de ellas fue rechazado e incluso algunos fueron revocados durante la presidencia de Agrelo. ${ }^{21}$

Caso singular era la medida que aclaraba que los escribanos europeos entraban en esta categoría, por lo que tenían ocho días en el caso de Buenos Aires para solicitar su título de ciudadanía (AGN, sala X, leg. 1739, f. 160), cuestión que le fue informada a Artigas -como máxima autoridad de la Banda Oriental revolucionariaen el mismo documento firmado por Agrelo donde se solicitaba la entrega de los títulos de sus respectivos diputados (Comisión Nacional Archivo Artigas, 1974, p. 56).

A los pocos días de esta decisión y aun durante la presidencia de Agrelo, su padre Inocencio presentó la solicitud de ciudadanía, la cual le fue otorgada sin reparos y firmada por su propio hijo (AGN, sala X, leg. 1739, f. 267). La situación se expresaba como respuesta a la falta de escribanos criollos y la preocupación de la Cámara de Apelaciones por definir la situación de los escribanos públicos ante las solicitudes de la Asamblea. Sin embargo, es de destacar que, junto con Inocencio, otro escribano peninsular de apellido Martínez hizo la misma solicitud, la cual fue rechazada por Agrelo por "no ser merecedor de la confianza", lo cual fue estipulado en la documentación donde informaba de la aceptación del título de su padre (AGN, sala X, leg. 1739, f. 275). Situación que se daba ante la prontitud de tiempos establecidos por el entonces presidente, lo cual podría haber frenado otras tantas presentaciones.

Con inmediatez se le informó de esta resolución al Cabildo de Buenos Aires, a fin de que tuviera presente las posibilidades de contar con el trabajo de Inocencio para las tareas notariales que había desempeñado en la época virreinal (AGN, 1928, p. 555).

De esa manera, Agrelo aseguró la conservación del oficio de su padre, mientras su hermano Marcos terminaba los estudios respectivos para suceder a su padre en la profesión de escribano público. Actitud similar tomó Agrelo durante su presidencia al dar títulos a españoles peninsulares miembros de familias revolucionarias y allegadas a él como el caso de Celedonio de Escalada. ${ }^{22}$ No fue así el caso del clérigo Melchor Fernández, allegado de Sarratea, cuyo título expidió la Asamblea bajo la presidencia de Valle y que fue rechazado por Agrelo y Alvear (AGN, 1897, p. 44).

Los títulos otorgados parecen arbitrarios con referencia a los rechazados, ya que no se evidenciaban ni describían razones puntuales más que cuestiones subjetivas sobre su carácter español. La validación de títulos a personas allegadas, contrastaba con los decretos aprobados durante la misma presidencia de Agrelo, en que se fortalecía lo estipulado sobre la expulsión de peninsulares de sus cargos de gobierno en especial en las provincias altoperuanas que empezaban a ser ocupadas por la expedición de Belgrano. Entre esos funcionarios se encontraba en la Audiencia de Charcas su suegro, José Calvimontes, quien en consecuencia sería desplazado de su cargo. Poco después de esta medida firmada por Agrelo, la Asamblea ya presidida por Larrea dispuso que la Audiencia fuera convertida en una Cámara de Apelaciones para que emulara el modelo institucional que la revolución acentuaba en Buenos Aires (El Redactor de la Asamblea, 8 de mayo de 1813, p. 4). Ello fue el fin de la carrera en la administración pública de su suegro.

En sus memorias, Agrelo no hizo alusión a la relación con sus parientes, ni al desplazamiento de Calvimontes, ni a la ciudadanía de Inocencio. Se centró en defender la lógica general del planteo jurídico, como forma de acentuar la configuración de un gobierno "independiente y nacional" (Agrelo, 1960, p. 1316), lo que subraya el carácter de intencionalidad legitimadora de dicha fuente.

La actitud de fortalecer la normativa ciudadana implicaba la creación de un distintivo entre los revolucionarios que conformaban la "comunidad política" que se constituía y los que no pertenecían a ella por diferencias ideológicas. Esta cuestión era permanentemente fortalecida por expresiones culturales y por otro tipo de normativas tendientes a diferenciar a quienes tomaban parte del proceso, de quienes no. En esta clave interpretativa puede analizarse también la declaración de la Asamblea presidida por Agrelo que señalaba 
que se debía subsidiar a aquellas personas inválidas producto de la guerra, pero que desde el 25 de mayo de 1810 hayan sido reconocidas por su servicio a la revolución (AGN, sala X, leg. 23-5-2).

Sin embargo, Agrelo fue apartándose progresivamente de la Asamblea, por sus disidencias internas en el alvearismo. Al momento de caer el directorio que encabezaba Alvear tras la Sublevación de Fontezuela, se inició una política de persecución contra la "facción" depuesta. Pese a sus diferencias, Agrelo fue considerado integrante de aquel grupo político y enjuiciado.

La Comisión Civil de Justicia integrada por Manuel Vicente Maza, Bartolomé Cueto y Juan García de Cossio, procedió de forma sumariante a los juicios establecidos. Agrelo fue acusado de predicar el "terror" y la "violencia". Consideraba en sus memorias que era la excusa para arrestarlo por verdaderas causas políticas y que una vez realizado se pudo demostrar que no tomó parte en aquella medida. Asimismo, Agrelo resaltó su falta de apoyo en la Asamblea a decisiones claves del alvearismo como la suspensión del Decreto de Seguridad Individual, al igual que la negación de su voto para el título de ciudadanía a un clérigo español que había ganado el apoyo general de los legisladores (Agrelo, 1960, p. 1321). ${ }^{23}$ La actitud de Agrelo había respondido a la lógica del grupo político al que había pertenecido, aunque hubiera tenido algunas diferencias coyunturales.

\section{Agrelo y el Estatuto Provincial de Entre Ríos: Nueva definición de “Ciudadanía”}

En su trayectoria, Agrelo se concentró en diversas cuestiones políticas y jurídicas, aunque no retomó la cuestión de la ciudadanía hasta su presencia en la provincia de Entre Ríos en 1822. Allí, arribo luego de los sucesos que lo tuvieron como protagonista en Buenos Aires en 1820, donde fue centro del denominado "motín del Cabildo", cuyo fracaso le causo el exilio en el Litoral. ${ }^{24}$

Mediante la recomendación de Francisco Martínez, consiguió el respaldo de Lucio Norberto Mansilla, a quien acompañó en los momentos en los que éste se convertiría en el nuevo gobernador de Entre Ríos. ${ }^{25}$ Bajo su administración se constituyó un grupo de letrados, de ideología federal, que entendía que se requería de una reorganización jurídica estable para fortalecer el poder político local e incrementar el desarrollo económico de la región. Agrelo pasó a desempeñarse como asesor del gobierno e integró ese grupo letrado que tomó la resolución de establecer un nuevo orden institucional.

Con ese objetivo, fue convocada una Convención Constituyente Provincial, de la cual Agrelo fue secretario y junto con Domingo del Oro fueron asesores de los redactores de la Constitución provincial en 1822. Si bien se les ha adjudicado a ambos la redacción del proyecto original, la documentación señala a otro letrado, Casiano Calderón, como su principal redactor (Bosch, 1943, p. 228) ${ }^{26}$ Es de suponer que el proyecto acabado fuera de este jurista, aunque el desempeño de Agrelo en la secretaría de la Convención le permitió participar de su diseño, siendo parte del grupo de juristas que estaba detrás del proyecto. Pese a su posterior alejamiento para integrar el cuerpo de ministros provinciales y su reemplazo en la secretaría de la Convención, Agrelo fue señalado como uno de los principales juristas que actuaron en la sanción del proyecto. El Estatuto tenía jerarquía constitucional y fue comunicado al gobernador el 13 de marzo de $1822,{ }^{27}$ el mismo día en que se juró la Independencia, pues al no haber integrado el Congreso de Tucumán, la provincia no se consideraba jurídicamente emancipada.

El Estatuto establecía en su primer artículo que la provincia de Entre Ríos se declaraba "un formal estado, y gobierno representativo, independiente" hasta que un "Congreso General de todas ellas [las provincias]" estableciera la "forma de gobierno" (EPCPER, 1822). De esa manera, se reconocía a la provincia como un estado independiente, pero con vocación de integración a las demás que reconocía. Esto coincidía con lo planteado únicamente por los estatutos de Córdoba y Salta (Goldman, 1998, p. 114), otras no harían mención de esta cuestión, lo que señala la falta de consenso al respecto, pero la idea de Agrelo y sus compañeros convencionales de que esto se produjera. Ello era reafirmado por el artículo $2^{\circ}$ que aclaraba que era "parte integrante de las Provincias Unidas del Río de la Plata y forma con todas una sola nación”. Ello permitía 
eliminar la expresión de República de Entre Ríos que había intentado exaltar Ramírez, en circunstancias de una secesión interna.

Luego de definir y precisar los límites de los tres poderes, se pasaba a la sección XI sobre los derechos particulares. Allí, primero se establecían las garantías de todos los "miembros del Estado" que en algunos de sus capítulos son referidos como "ciudadanos". Los derechos señalados con especificidad son de vida, reputación, propiedad y libertad (EPCPER, 1822). La definición de los ciudadanos aparece recién en la siguiente sección. Es notorio que primero el proyecto constituyera una visión general de la estructura política, luego especificara las garantías de sus integrantes para recién entonces definir y precisar al portador de aquella soberanía replantada. El orden argumental es diferente al del proyecto de la Comisión oficial de 1813, donde la precisión de la ciudadanía estaba al principio como organizador de todo el cuerpo jurídico. Eso se podría deber a la necesidad de aquel momento por definir al sujeto soberano, mientras que en aquel otro contexto provincial primaba la organización de un sistema institucional sobre bases relativamente aceptadas y sujetas a las consideraciones del referido Congreso General que se debía convocar.

Al momento de especificar el alcance de la ciudadanía, el Estatuto Provincial establecía una concepción diferente a la del proyecto de 1813. Señalaba que "son ciudadanos y gozan de todos los derechos de tales, activos y pasivos en la provincia, conforme a la declaración de este Estatuto, todos los hijos nativos de ella y demás americanos, naturales de cualquier pueblo o provincia de los territorios que fueron españoles en ambas Américas, que residan en ella en presente o residiesen en adelante" (EPCPER, 1822). De esa manera, se eliminaban relevantes restricciones para el acceso a la ciudadanía. Todo americano podría ser concebido como tal, dado su carácter "nativo", lo que implicaba la aplicación de ius soli donde se era ciudadano por haber nacido en el lugar determinado. A su vez, seguía la alusión al carácter residencial, lo cual permanecía sin aclaración en cuanto a si era un requisito de propiedad o no.

Especificaba el carácter del ciudadano como portador soberano, señalar que todo hombre que accediera a cualquier cargo de gobierno debería tener tal categoría. Se especifica así el derecho de votar y ser votado. No obstante, la ciudadanía les era negada a ciertos individuos como los condenados a pena de muerte o destierro, al igual que los "dementes", los "deudores quebrados de mala fe", los esclavos y los niños que no alcanzaran los dieciocho años (EPCPER, 1822). Si bien estas salvedades responden a un marco conceptual de la época (Guerra, 1999, p. 48), el Estatuto especifica más adelante otras restricciones de la ciudadanía, lo que acaba por convertir a su portación en un aspecto de privilegio y distinción.

Ello se evidencia en su artículo 115 donde se señala que "tienen suspendidos estos derechos [los de ciudadanía] los que no tienen empleos, oficio u ocupación útil, o modo de vivir honesto y conocido; y aquellos por último a quienes se prive de su goce por interdicción judicial" (EPCPER, 1822). Así, se establecía una salvedad al portador de la soberanía. Podía mantener "suspendido" su carácter si no demostraba ser un miembro "útil" a la sociedad o era condenado en tal carácter. Esa posibilidad de negar la ciudadanía era un instrumento que conservaba el gobierno para limitar la participación política si así lo necesitara. Ponía límites a la actividad de sectores bajos que podrían ser objeto de "movimientos de pueblos" o alteraciones políticas.

Entre las últimas restricciones, se estipulaba que hacia 1840 perderían el carácter de ciudadano los analfabetos, lo que señala la intencionalidad de sostener una reformación educativa amplia y extendida en la provincia, la cual debía estar volcada a "formar al ciudadano", convertir a los jóvenes en sujetos soberanos. La exclusión de los analfabetos no podía ser establecida en ese momento, dado los bajos niveles de alfabetización existentes en la provincia (Salvadores, 1966, p. 29-30), pero se establecía una marca futura donde este principio pasaría a actuar de forma restrictiva.

Por otra parte, se separaba la concepción de esta ciudadana nativa, con la "naturalización" del extranjero, singularidad no presente con claridad en la participación jurídica de Agrelo en la década anterior. Allí permanece la idea de los "límites de la soberanía provincial" al señalar que la naturalización le competerá únicamente al Congreso General que se debería convocar. 


\section{CONSIDERACIONES FINALES}

A lo largo de su trayectoria jurídica Agrelo debió trabajar sobre el concepto de "ciudadanía” en dos momentos esenciales, durante su actividad en la Asamblea del Año XIII y en su participación de la redacción del Estatuto Provisional de Entre Ríos. En ambas oportunidades, se debía priorizar el alcance teórico del concepto, el cual estaba en permanente cambio al tomar autonomía de la categoría de "vecino" y de "natural". Era un momento de transición, donde su uso era cambiante y superpuesto a otros lenguajes.

En ese proceso, los proyectos constitucionales de que los que participó Agrelo evidencian una transformación del concepto. El letrado participó de grupos políticos y jurídicos desde donde tomó parte de los proyectos constitucionales que en 1813 y 1822 adaptaron este concepto como parámetro para la tipificación del sujeto soberano, sobre el que se debía estructurar el Estado que se intentaba configurar. En consecuencia, su uso era una forma de desplazar las categorías jerárquicas y monárquicas vigentes hasta entonces.

Mientras que en 1813 había una política restrictiva, dado que existía la necesidad de generar una ruptura marcada con el peninsular que no fuera decididamente revolucionario, en 1820 se encontraba frente a la necesidad de incorporar ciudadanos que sirvieran al desarrollo provincial. La convocatoria de una amplia ciudadanía americana en el Estatuto permitía una aparente ampliación del derecho, aunque las salvedades especificadas son mayores que en la Asamblea del Año XIII. Las restricciones por condición social y a futuro por analfabetismo, implicaban constituir herramientas políticas que pudieran ser utilizadas por los gobiernos provinciales para controlar el ejercicio de la soberanía, es decir, de la participación política. Bajo el mismo sentido semántico, se creaba una restricción práctica a fin de evitar y contener situaciones de "desborde social" como las generalizadas en esos años. Así, se produjo un cambio de problema o de amenaza para la estabilidad institucional que se buscaba.

De esa manera, ambos trabajos jurídicos buscaron cimentar un sistema de carácter republicano y participativo, aunque con prácticas ambiguas que permitían garantizar el "orden" institucional pretendido. Ello estaba en relación con la situación personal de Agrelo, quien desde sus cargos en la Asamblea promovió la entrega de ciudadanía a peninsulares allegados al gobierno - como su padre- mientras endurecía su posición hacia el común de los españoles europeos. Esa situación sería distinta en 1822, cuando el elemento peninsular de la sociedad dejó de ser un problema y no existía ya la generalizada necesidad de los criollos por incorporar como ciudadano a parientes o allegados. Por ese motivo, la naturalización de los extranjeros quedaba postergada para el Congreso General, ya que en términos prácticos no era de preocupación central para el gobierno provincial. Si lo era en cambio, la regularización de la participación política de ciertos grupos sociales provenientes de los estratos más bajos de los criollos, situación no evidenciada en 1813.

\section{BiBLIOgRAFÍA}

Aljovin de Losada, C. (2014). Ciudadano y vecino en Iberoamérica, 1750-1850: Monarquía o República. En: Fernández Sebastián, J. (dir.). Diccionario político y social del mundo iberoamericano. Iberconceptos II (Vol. 10, pp. 179-210). Madrid: Universidad del País Vasco Euskal Herriko Unibersitatea / Centro de Estudios Políticos y Constitucionales.

Aninno, A. y Ternavasio, M. (coords.) (2012). El laboratorio constitucional iberoamericano: 1807/1808-1830. Madrid: Iberoamericana - Estúdios ahila.

Bosch, B. (1943). El estatuto provisorio constitucional de Entre Ríos. En: Boletín del Instituto de Investigaciones Históricas. Tomo XXVII. No 93-96. Buenos Aires: Universidad de Buenos Aires.

Botana, N. (1991). La Libertad Politica y su Historia. Buenos Aires: Ed. Sudamericana.

Canter, J. (1960). La Asamblea General Constituyente. En Academia Nacional de la Historia. Historia de la Nación Argentina. V. 6. tomo I. Buenos Aires: Academia Nacional de la Historia. 
Cansanello, O. (2001) Itinerarios de la Ciudadanía en Buenos Aires, La ley de elecciones de 1821. En: Prohistoria. Año V. número 5.

Cansanello, O. (2003). De súbdito a ciudadanos. Ensayo sobre las libertades en los orígenes republicanos, Buenos Aires (1810-1852). Buenos Aires: Ediciones Imago Mundo.

Chiaramonte, J. C. (1997). Ciudades, provincias, Estados: Orígenes de la Nación Argentina (1800-1846). Buenos Aires: Ariel.

Chiaramonte, J. C. (1999). Ciudanía, soberanía y representación en la génesis del Estado argentino (1810-1852). En: Sábato, H. (Coord.). Ciudadanía politica y formación de las naciones (pp. 105-106). México: Fondo de Cultura Económica.

Chiaramonte, J. C. (2000) Fundamentos Iusnaturalistas de los movimientos de Independencia. En Boletín del Instituto de Historia Argentina y Americana "Dr. Emilio Ravignani". Tercera serie. núm. 22. 2 semestre.

Chiaramonte, J. C. (2004). Nación y Estado en Iberoamérica: El lenguaje político en los tiempos de las independencias. Buenos Aires: Sudamericana.

Chiaramonte, J. C. (2007). La ilustración en el rio de la plata. Buenos Aires: Sudamericana.

De Marco, M. Á. (2006). Historia del periodismo argentino. Buenos Aires: Educa.

Di Meglio, G. (2007). Milicia y política en la ciudad de Buenos Aires durante la Guerra de Independencia (1810-1820). En: Chust, M. y Marchena, J. (Eds.). Las armas de la Nación. Independencia y ciudadania en Hispanoamérica (1750-1850). (pp. 137-158). Madrid: Iberoamericna.

Eiris, A. A. (2015). El jurista Pedro José Agrelo y su colaboración en el proyecto de Constitución elaborado por la Comisión Oficial en la Asamblea del Año XIII. En: Revista de Historia del Derecho. № 50. Buenos Aires: Instituto de Historia del Derecho. Julio-diciembre.

Eiris, A. A. (2014). La concepción continental de la guerra revolucionaria en el discurso periodístico de Pedro José Agrelo desde la Gazeta de Buenos Ayres en 1811. En: Épocas. No 9. Buenos Aires: Universidad del Salvador.

Fúrlong, G. (1952). Nacimiento y desarrollo de la filosofia en el Rio de la Plata, 1536-1810. Buenos Aires: Kraft.

García Belsunce, C. A. y Floria, C. (1971). Historia de los argentinos. tomo I. Buenos Aires: Kapeluz.

Goldman, N. y Pasino, A. (2008). Opinión pública. En: Goldman, N. (ed.). Lenguaje y revolución: conceptos politicos clave en el Río de la Plata, 1780-1850. Buenos Aires: Prometeo.

Goldman, N. (1998). Los orígenes del federalismo rioplatense. En: Goldman, N. (Dir.). Nueva Historia Argentina. Revolución, república y confederación (1806-1852). Buenos Aires: Sudamericana.

González Bernarndo, P. (1991). La Revolución Francesa y la emergencia de nuevas prácticas de la política: La irrupción de la sociabilidad política en el Río de la Plata revolucionario (1810-1815). En: Boletín del Instituto de Historia Argentina y Americana "Dr. E. Ravignani” (pp. 7-27). tercera serie. № 3. Buenos Aires.

Guerra, F. X. (1999). El soberano y su renio. Reflexiones sobre la génesis del ciudadano en América Latina. En: Sábato, H. (dir.) Ciudadania politica y formación de las naciones. Perspectivas históricas de América Latina. México: Fondo de Cultura Económico.

Halperín Donghi, T. (1972). Revolución y guerra: Formación de una élite dirigente en la Argentina criolla. Buenos Aires: Siglo XXI.

Halperin Donghi, T. (1985). Tradición Politica Española e Ideología Revolucionaria de Mayo. Buenos Aires: Centro editor de América Latina.

Herrera, C. M. (2008). Los derechos sociales, entre Estado y doctrina jurídica, Bogotá, Universidad Externado de Colombia.

Herrero, F. (2003). Un golpe de Estado en Buenos Aires durante octubre de 1820. En: Anuario IEHS. № 18. Tandíl.

Herzog, T. (2006). Vecinos y extranjeros. Hacerse español en la Edad Moderna. Madrid: Alianza.

Koselleck, R. (1993). Futuro pasado. Para una semántica de los tiempos históricos Buenos Aires: Paidos.

Levene, R. (1921). Ensayo histórico sobre la Revolución de Mayo y Mariano Moreno. 2 tomos. Buenos Aires: Facultad de Derecho y Ciencias Sociales. 
Ariel Alberto Eiris. El uso del concepto de “ciudadanía” en el trabajo jurídico de Pedro José Agre...

Martiré, E. y Tau Anzoátegui, V. (2012). Manual de historia de las Instituciones Argentinas. Buenos Aires: Histórica.

Molina, E. (2002). El concepto de ciudadanía en el discurso y en las prácticas de las "modernas" formas de sociabilidad asociativa (1810-1813). En: Sociohistórica. núms. 11-12. Universidad Nacional de la Plata.

Myers, J. (2008). El letrado patriota: los hombres de las letras hispanoamericanos en la encrucijada del colapso del imperio español en América. En: Carlos A. (Comp.), Historia de los intelectuales en América latina. Volumen I. (pp. 121-144). Buenos Aires: Katz Editores.

Palti, E. J. (2007). El tiempo de la Política. El siglo XIX reconsiderado. Buenos Aires: Siglo XXI Editores.

Pérez Guilhou, D, (1999). “Pensamiento político y proyectos constitucionales (1810-1880)”. En: Academia Nacional de la Historia. Nueva Historia de la Nación Argentina. tomo V.

Pérez Ledesma, M. (Coord.). (2008). De súbditos a ciudadanos. Una historia de la ciudadania en España. Madrid: Centro de Estudios Constitucionales.

Portillo Valdés, J. M. (2009). "Ex unum, pluribus: revoluciones constitucionales y disgregación de las monarquías iberoamericanas”. En: Fernández Sebastián, J. (Dir.), Diccionario político y social del mundo iberoamericano. La era de las revoluciones 1750-1850. Iberconceptos I. (pp. 307-335). Madrid: Fundación Carolina -Sociedad Estatal de Conmemoraciones Culturales - Centro de Estudios Políticos y Constitucionales.

Pujol, G. (2004). “Un rey, una fe, muchas naciones. Patria y nación en la España de los siglos XVI-XVII”. En: AlvarezOsorio A., A., y García García, B. La monarquía de las naciones. Patria, nación y naturales en la Monarquía de España. Madrid: Fundación Carlos Amberes.

Ravignani, E. (1927). Historia constitucional de la República Argentina. Volumen 2. Buenos Aires: Peuser.

Rosanvallon, P. (1999). La consagración del ciudadano. Historia del sufragio universal en Francia. México: Instituto Mora.

Ruiz Moreno, M. (1914) Contribución a la historia de Entre Ríos. Tomo II. Buenos Aires: La Facultad.

Sábato, H. y Ternavasio, M. (2011). "El voto en la República. Historia del sufragio en el siglo XIX”. En: Sábato, H. Ternavasio, M., De Privitellio, L. y Persello, A. V. Historia de las elecciones en la Argentina (1805-2011). Buenos Aires: El Ateneo.

Sábato, H. (1999). Ciudadanía politica y formación de las naciones. Perspectivas históricas de América Latina. México: Fondo de Cultura Económico.

Salvadores, A. (1966). Historia de la instrucción pública en Entre Ríos. Paraná: Museo Histórico de Entre Ríos "Martiniano Leguizamón".

Salvatto, F. y Banzato, G. (2017). "Naturales, vecinos y extranjeros en el ejercicio de cargos públicos y oficios. Buenos Aires (ciudad y campaña), 1812-1815”. en: Revista de Indias. № 269. vol. LXXVII. (pp. 169-195). Madrid.

Salvatto, F. y Carzolio, M. I. (2015). “Naturaleza y ciudadanía en la España Moderna. De la representación del súbdito a los albores de la ciudadanía contemporánea (siglos XVII-XIX)”. En:Almanack. Guarulhos. №11. (pp. 670-706).

Tanzi, H. (2000). "Concepto histórico y constitucional de "vecino"”. En: Academia Nacional de la Historia. Sexto congreso nacional y regional de historia argentina. Tomo II. Buenos Aires: Academia Nacional de la Historia.

Tau Anzoátegui, V. (1965). Formación del Estado Federal Argentino, 1829-1852: la intervención del gobierno de Buenos Aires en los asuntos nacionales. Buenos Aires: Editorial Perrot.

Tau Anzoátegui, V. (2008). La codificación en la Argentina (1810-1870). Mentalidad social e ideas jurídicas. Buenos Aires: Perrot.

Ternavasio, M. (2007). Gobernar la revolución. Poderes en disputa en el Rio de la Plata (1810-1816). Buenos Aires: Siglo XXI.

Williams, R. (2003). Palabras claves. Un vocabulario de la cultura y la sociedad. Buenos Aires: Nueva Visión.

Zorraquín Becú, R. (1966). Historia del derecho argentino. Tomo II (1810-1969). Buenos Aires: Editorial Perrot. 


\section{Fuentes InÉditas}

Archivo General de la Nación Argentina, Sala X, Asamblea General Constituyente, Legajo 1739.

Archivo General de la Provincia de Entre Ríos, Sección Gobierno, legajo 8.

Archivo Histórico del Museo Histórico Nacional, Fondo Donación/Adquisición, Sección Documentos de Mayo.

\section{Periódicos}

Gazeta de Buenos Ayres, Buenos Aires, 1813.

Gazeta Ministerial, Buenos Aires, 1813.

El Redactor de la Asamblea, Buenos Aires, 1813.

\section{Fuentes Editas}

"Proyecto de Constitución para las Provincias del Río de la Plata, formado por una Comisión Especial, nombrada en 1812”. (1932). En: Universidad de la República. Biblioteca de Impresos raros americanos, tomo V, Montevideo: Universidad de la República.

Agrelo, P. J. (1960). “Autobiografía”. En: Biblioteca de Mayo. Tomo II. Buenos Aires: Honorable Senado de la Nación. Archivo General de la Nación. (1928). Acuerdos del Extinguido Cabildo de Buenos Aires 1812-1813, Serie IV. Tomo V. Buenos Aires: Kraft.

Archivo General de la Nación. (1897). Periodo de la Independencia: Año 1815. Proceso de Residencia. Tomo XIII. Buenos Aires: Kraft.

Comisión Nacional Archivo Artigas. (1974), Archivo Artigas. Tomo 11. Advertencia de Juan Pivel Devoto. Montevideo: Impresores Monteverde.

Estatuto provisorio constitucional de la provincia de Entre Ríos en el Río de la Plata en la América del Sur: sancionado y publicado en 4 de marzo de 1822. (1822). Paraná: Impr. de la Independencia.

\section{Notas}

1 Una primera versión de este trabajo fue presentada en el Ciclo de Lecturas en Diálogo, organizado por el Centro de Historia Argentina y Americana, de la Universidad Nacional de La Plata el día 5 de abril de 2018. Agradezco a sus coordinadores Juan Bubello y Julián Carrera, además de quienes me hicieron una profunda devolución en dicha oportunidad: Fernando Barba, Facundo Lafit, Guillermo Quinteros y Fabricio Gabriel Salvatto. César A. García Belsunce también realizó una lectura preliminar de este trabajo.

2 Entre las obras que abordan, desde diversas perspectivas, aspectos disímiles del período histórico en cuestión y que contienen consideraciones sobre el accionar de Agrelo se destacan las referidas a la historia jurídica y política. Entre todas ellas se pueden mencionar como referencia a: Levene (1921); Ravignani (1927); Fúrlong (1952); Tau Anzoátegui (1965); Zorraquín Becú (1966); García Belsunce y Floria (1971); Halperín Donghi (1972); Botana (1991); Chiaramonte (2004); De Marco (2006); Ternavasio (2007); Goldman y Pasino (2008).

3 La tesis de nuestra autoría se titula Un letrado en busca de un Estado: Discursos y acción en la trayectoria politico-jurídica de Pedro José Agrelo. Se encuentra en actual desarrollo en la Universidad del Salvador en el marco de la Beca Interna Doctoral de Conicet-Argentina.

4 El "momento constitucional" refiere a una "imagen" plasmada en el discurso jurídico de lenguajes y concepciones circulantes y cambiantes. Estas conceptualizaciones son utilizadas entre otros por Carlos Herrera al abordar la historia y la filosofía del derecho. Conf. Miguel Herrera (2008).

5 Se entiende que cada concepto posee un contexto propio que le da sentido y un uso que la resignificativiza. Para ello ver los diversos aportes de Williams (2003) y Koselleck (1993).

6 Un modelo de análisis al respecto es Rosanvallon (1999).

7 Es necesario precisar las connotaciones del concepto de "letrado", el cual refería tanto al alfabetizado, como "al que trabaja con las letras" mediante un desempeño intelectual en su sentido amplio. El letrado queda entonces asociado al concepto 
de intelectual solamente en cuanto "experto en el manejo de los recursos simbólicos", es decir persona especializada en el uso de sus capacidades intelectuales al momento de estudiar la realidad y elaborar representaciones y explicaciones que dieran sentido a sus percepciones. Es entonces un hacedor de cultura escrita. Ver: Myers (2008, p. 121-144).

8 Este eclecticismo intelectual caracterizado por la integración de conceptos escolásticos con los modernos principios ilustrados, puede verse en: Chiaramonte (2007, p. 91).

9 Ello fue trabajado en: Eiris (2014).

10 Muchas de estas primeras cartas debieron ser revalidadas por los gobiernos revolucionarios sucesivos, como consecuencia de haber sido entregadas por la arbitrariedad de los grupos políticos del momento, según sus necesidades.

11 Posadas se incorporó en la Comisión Oficial poco antes de que Córdoba lo nombrara diputado. En el caso de Chorroarín, compartió la Comisión con Agrelo, quien fue su pupilo en el Colegio San Carlos y a quien sancionó por fugarse reiteradas veces.

12 En el caso de Nicolás Herrera se había desempeñado como secretario del Triunvirato y agente diplomático suyo a la vez que redactaba la Gazeta Ministerial que representaba el órgano oficial de aquel gobierno. Pese a ello sostuvo en sus escritos un discurso promotor de las categorías de independencia y se alejó progresivamente de Rivadavia para integrarse a los sectores de la Sociedad Patriótica.

13 La misma ambigüedad semántica se encontraba presente en los discursos constitucionales peninsulares, en especial en los escritos de Melchor Gaspar de Jovellanos (Palti, 2007, p. 62-66). La iniciativa de crear un único texto constitucional se remonta a los discursos de Thomas Paine.

14 El documento referido se titula Proyecto de Constitución para las Provincias del Río de la Plata, formado por una Comisión Especial, nombrada en 1812 (en adelante PCPRP), reproducido en Universidad de la República (1932).

15 Estos aspectos y su articulación han sido trabajados en Eiris, (2015). En la presente investigación nos centraremos solamente en lo vinculado a su concepción de ciudadanía.

16 Esfuerzos jurídicos similares se realizaban en las Cortes de Cádiz, donde Argüelles señaló la necesidad de definir jurídicamente el concepto de "ciudadano" para diferenciar del de vecino. Ello representaba la idea de crear una ruptura conceptual, aunque los elementos corporativistas se expresaran en otros aspectos del modelo constitucional. Al respecto consultar: Guerra (1999, p. 40 y 43 ).

17 Los antecedentes de esta cuestión se encuentran en la orden del 6 de diciembre que había impulsado Moreno, mediante la cual sólo los criollos podían ser electos como funcionarios públicos. Luego, el decreto del 21 de marzo emitido por la Junta Grande que decidía expulsar a los españoles solteros. Hecho que ocasionó en su momento el rechazo de la Sociedad Patriótica que contaba con el apoyo y la defensa periodística de Agrelo.

18 Ello era diferente del modelo gaditano, donde las Cortes establecieron exigencias puntuales para la otorgación del título de ciudadano. Requisitos similares fueron recién adoptados en el Río de la Plata en 1815, cuando dichos criterios habían tenido una notable difusión. Conf. Pérez Ledesma (2008).

19 Dentro del policentrísmo monárquico, el rey tenía tantas "naturalezas" como reinos que gobernaba, sin importar su lugar de nacimiento. Eso le daba la condición de darle a cualquier súbdito una carta de natural según las condiciones de servicio que él mismo ofreciera (Pujol, 2004, p. 52).

20 Ver: Bando del triunvirato presentando la expulsión de españoles no ciudadanos por pedido de la asamblea, en: Biblioteca de Mayo (1960, p. 16749). El 23 de marzo la Asamblea dictó una interpretación del decreto señalando que "europea" refería al "español europeo". Ver El Redactor de la Asamblea (27 de marzo de 1813).

21 Conf. Archivo General de la Nación Argentina (en adelante AGN), Sala X, Asamblea General Constituyente, Legajo 1739, f. 239.

22 Carta de ciudadanía dada el 27 de abril de 1813 (Archivo Histórico del Museo Histórico Nacional, Fondo Donación/ Adquisición, Sección Documentos de Mayo, F 13419, M 24).

$23 \mathrm{Al}$ respecto sólo existe como fuente la versión de Agrelo, puesto que El Redactor de la Asamblea no especificó qué diputado se abstuvo o votó en contra. Si el pedido de ciudadanía al que Agrelo se opuso es el referido en la declaración de Valle sobre el clérigo Melchor Fernández, la misma fue apoya por Alvear a tal punto que el declarante confunde quien de los dos fue el de la moción en su contra y quién el que la apoyó. Lo que derrumbaría este argumento de Agrelo, pues habría actuado en convivencia con Alvear, líder de la facción dominante (AGN, 1928, p. 44).

$24 \mathrm{Al}$ respecto consultar: Herrero (2003).

25 Carta de Francisco Martínez a Lucio N. Mansilla, 12 de diciembre de 1820 (Archivo General de la Provincia de Entre Ríos, Sección Gobierno, legajo 8).

26 La participación de Agrelo como jurista fue resaltada documentalmente en Ruiz Moreno (1914, p. 23).

27 Es titulado: Estatuto provisorio constitucional de la provincia de Entre Ríos en el Río de la Plata en la América del Sur: sancionado y publicado en 4 de marzo de 1822. En adelante EPCPER

\section{BY-NC-SA}

